\title{
Systemic Racism and Health Disparities: A Statement From Editors of Family Medicine Journals
}

\author{
Sumi M. Sexton, $M D^{1}$ \\ Caroline R. Richardson, $M D^{2}$ \\ Sarina B. Schrager, $M D, M S^{3}$ \\ Marjorie A. Bowman, MD \\ Jobn Hickner, MD, MSc ${ }^{5}$ \\ Christopher P. Morley, PbD, MA \\ Timothy F. Mott, $M D^{7}$ \\ Nicholas Pimlott, $M D, P b D^{8}$ \\ Jobn W. Saultz, $M D^{9}$ \\ Barry D. Weiss, $M D^{10}$ \\ ${ }^{1}$ American Family Physician \\ ${ }^{2}$ Annals of Family Medicine \\ ${ }^{3} \mathrm{FPM}$ \\ ${ }^{4}$ Journal of the American Board of Family \\ Medicine \\ ${ }^{5}$ The Journal of Family Practice \\ ${ }^{6}$ PRiMER \\ ${ }^{7}$ FPIN/Evidence Based Practice \\ ${ }^{8}$ Canadian Family Physician \\ ${ }^{9}$ Family Medicine \\ ${ }^{10} \mathrm{FP}$ Essentials
}

Conflicts of interest: authors report none.

\section{CORRESPONDING AUTHOR}

Sumi M. Sexton, MD

Georgetown University 4000 Reservoir Rd, NW Washington, DC 20057 makkars@georgetown.edu
Ann Fam Med 2021;19:2-3. https://doi.org/10.1370/afm.2613.

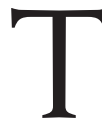
The year 2020 has been marked by historic protests across the United States and the globe sparked by the deaths of George Floyd, Ahmaud Arbery, Breonna Taylor, and so many other Black people. The protests heightened awareness of racism as a public health crisis and triggered an antiracism movement. Racism is a pervasive and systemic issue that has profound adverse effects on health. ${ }^{1,2}$ Racism is associated with poorer mental and physical health outcomes and negative patient experiences in the health care system. ${ }^{3,4}$ As evidenced by the current coronavirus pandemic, race is a sociopolitical construct that continues to disadvantage Black, Latinx, Indigenous, and other People of Color. ${ }^{5-8}$ The association between racism and adverse health outcomes has been discussed for decades in the medical literature, including the family medicine literature. Today there is a renewed call to action for family medicine, a specialty that emerged as a counterculture to reform mainstream medicine, ${ }^{9}$ to both confront systemic racism and eliminate health disparities. This effort will require collaboration, commitment, education, and transformative conversations around racism, health inequity, and advocacy so that we can better serve our patients and our communities.

The editors of several North American family medicine publications have come together to address this call to action and share resources on racism across our readerships. We acknowledge those members of the family medicine scholar community who have been fighting for equity consistent with the Black Lives Matter movement by writing about racism, health inequities, and personal experiences of practicing as Black family physicians. While we recognize that much more work is needed, we want to amplify these voices. We have compiled a bibliography of scholarship generated by the family medicine community on the topic of racism in medicine.

The collection can be accessed here: https:/www.AnnFamMed.org/ content/shared-bibliography-systemic-racism-and-health-disparities.

While this list is likely not complete, it does include over 250 published manuscripts and demonstrates expertise as well as a commitment to addressing these complex issues. For example, in 2016, Dr J. Nwando Olayiwola, chair of the Department of Family Medicine at Ohio State University, wrote an essay on her experiences taking care of patients as a Black family physician. ${ }^{10}$ In January of 2019, Family Medicine published an entire issue devoted to racism in education and training. ${ }^{11}$ Dr Eduardo Medina, a family physician and public health scholar, co-authored a call to action in 2016 for health professionals to dismantle structural racism and support Black lives to achieve health equity. His recent 2020 article builds on that theme and describes the disproportionate deaths of Black people due to racial injustice and the COVID-19 pandemic as converging public health emergencies. ${ }^{12,13}$ In the wake of these emergencies a fundamental transformation is warranted, and family physicians can play a key role. 
We, the editors of family medicine journals, commit to actively examine the effects of racism on society and health and to take action to eliminate structural racism in our editorial processes. As an intellectual home for our profession, we have a unique responsibility and opportunity to educate and continue the conversation about institutional racism, health inequities, and antiracism in medicine. We will take immediate steps to enact tangible advances on these fronts. We will encourage and mentor authors from groups underrepresented in medicine. We will ensure that content includes an emphasis on cultural humility, diversity and inclusion, implicit bias, and the impact of racism on medicine and health. We will recruit editors and editorial board members from groups underrepresented in medicine. We will encourage collaboration and accountability within our specialty to confront systemic racism through content and processes in all of our individual publications. We recognize that these are small steps in an ongoing process of active antiracism, but we believe these steps are crucial. As editors in family medicine, we are committed to progress toward equity and justice.

Simultaneously published in American Family Pbysician, Annals of Family Medicine, Canadian Family Pbysician, Family Medicine, FP Essentials, FPIN/Evidence Based Practice, FPM, Journal of the American Board of Family Medicine, The Journal of Family Practice, and PRiMER.

To read or post commentaries in response to this article, see it online at https:/lwww.AnnFamMed.org/content/19/1/2.

Key words: racism; racial bias; racial discrimination; racial prejudice; family medicine; primary care; health disparities; delivery of health care Submitted October 5, 2020; accepted October 5, 2020.

Acknowledgments: The authors thank Renee Crichlow, MD, Byron Jas per, MD, MPH, and Victoria Murrain, DO for their insightful comments on this editorial.

\section{References}

1. Institute of Medicine, Committee on Understanding and Eliminating Racial and Ethnic Disparities in Health Care, Board on Health Sciences Policy, Smedley BD, Stith AY, Nelson AR, eds. Unequal Treatment: Confronting Racial and Ethnic Disparities in Health Care. National Academies Press; 2003.

2. Bailey ZD, Krieger N, Agénor M, Graves J, Linos N, Bassett MT. Structural racism and health inequities in the USA: evidence and interventions. Lancet. 2017;389(10077):1453-1463.

3. Ben J, Cormack D, Harris R, Paradies Y. Racism and health service utilisation: a systematic review and meta-analysis. PLOS One. 2017; 12(12):e0189900.

4. Paradies $Y$, Ben J, Denson N, et al. Racism as a determinant of health: a systematic review and meta-analysis. PLoS One. 2015; 10(9):e0138511.

5. American Academy of Family Physicians. Institutional racism in the health care system. Published 2019. Accessed Sep 15, 2020. https:// www.aafp.org/about/policies/all/institutional-racism.html

6. Yaya S, Yeboah H, Charles CH, Otu A, Labonte R. Ethnic and racial disparities in COVID-19-related deaths: counting the trees, hiding the forest. BMJ Glob Health. 2020;5(6):e002913.

7. Egede LE, Walker RJ. Structural racism, social risk factors, and Covid-19-a dangerous convergence for Black Americans [published online ahead of print July 22, 2020]. N Engl J Med. 2020;383(12): e77. https://doi.org/10.1056/NEJMp2023616

8. Centers for Disease Control and Prevention. Health equity considerations and racial and ethnic minority groups. Updated Jul 24, 2020. Accessed Sep 15, 2020. https://www.cdc.gov/coronavirus/2019ncov/community/health-equity/race-ethnicity.html

9. Stephens GG. Family medicine as counterculture. Fam Med. 1989; 21(2):103-109.

10. Olayiwola JN. Racism in medicine: shifting the power. Ann Fam Med. 2016;14(3):267-269. https://doi.org/10.1370/afm.1932

11. Saultz J, ed. Racism. Fam Med. 2019;51(1):1-66.

12. Hardeman RR, Medina EM, Kozhimannil KB. Structural racism and supporting black lives - the role of health professionals. N Engl J Med. 2016;375(22):2113-2115. https://doi.org/10.1056/ NEJMp1609535

13. Hardeman RR, Medina EM, Boyd RW. Stolen Breaths. N Engl J Med. 2020;383(3):197-199. https://doi.org/10.1056/NEJMp2021072 